\title{
Karl Marx, un periodista en la Era del Capital. Apuntes para una investigación
}

\author{
Karl Marx, a journalist in the Era of Capital. \\ Notes for a research.
}

MARIO ESPINOZA PINO

Universidad Complutense, Madrid

RESUMEN. El objetivo de este artículo es criticar la representación tradicional del trabajo periodístico de Karl Marx, habitualmente olvidado por un canon engañoso que sólo asume sus artículos al precio de convertirlos en una obra menor. Uno de los problemas de esta concepción tradicional es que disocia sus contribuciones teóricas y económicas del desarrollo histórico del pensamiento del autor (y también de sus raíces materiales). Intentaremos señalar la importancia del periodismo maduro de Karl Marx en dos áreas: en la construcción de los conceptos centrales de su crítica contra el capitalismo (plusvalor, un enfoque histórico multilineal, una descripción global del mercado mundial, etc.) y en la producción de cartografías políticas para intervenir en el conflicto de clases. Este artículo plantea varias hipótesis y afirmaciones tentativas sobre el periodismo de Karl Marx que pueden servir como punto de partida de una investigación crítica.

Palabras clave: Karl Marx, periodismo, New York Tribune, historia multilineal, mapas antagonistas
ABSTRACT. The aim of this article is to criticize the traditional representation of Karl Marx's journalistic works, usually forgotten by a misleading canon that assumes his articles only as a minor work. One of the problems of this traditional conception is that it dissociates his theoretical and economic contributions from the historical development of the author's thought (and also from its material roots). We will try to point the importance of Karl Marx's mature journalism in two areas: in the construction of the central concepts of his critic against the capitalist mode of production (surplus value, a multilineal historical perspective, a global description of the world market, etc.) and in the production of political cartographies to intervene in the class conflict. This article poses several hypothesis and tentative affirmations about Karl Marx's journalism that may serve as a point of departure for a critical research.

Key Words: Karl Marx, journalism, New York Tribune, mulilineal history, antagonistic maps 
Parole, orage, glace et sang finiront par former un givre commun.

RENÉ CHAR

\section{Karl Marx y el periodismo: más allá del olvido}

Resulta sorprendente que a día de hoy no dispongamos todavía de un estudio serio y riguroso acerca de la actividad periodística de Karl Marx. Existen innumerables artículos y libros sobre su pensamiento teórico y político, por no hablar de la imponente bibliografía generada en torno a sus contribuciones más conocidas, desde sus tempranos Manuscritos de París (1844) hasta El Capital (1867). Sin embargo, los artículos del filósofo de Tréveris parecen haber sido sepultados bajo el peso de sus grandes obras, desplazados a un ámbito marginal y aparentemente anecdótico en el marco de su producción teórica. Un gesto que no deja de rayar en lo paradójico, sobre todo si tenemos en cuenta la importancia del periodismo en la formación de Marx y en el desarrollo de su crítica de la economía política. Lo cierto es que la tradición marxista, generación tras generación, ha terminado por convertir los escritos periodísticos del pensador en un suerte de "fuente secundaria" o "literatura menor": en el mejor de los casos han servido de instrumento auxiliar a historiadores e investigadores, permitiéndoles perfilar mejor el trasfondo histórico de su pensamiento; también se han mostrado útiles a la hora de resolver ambigüedades interpretativas puntuales. Pero más allá de estos usos limitados, el periodismo de Marx nunca ha sido abordado de manera autónoma, es decir, como una línea de investigación específica que merezca ser recorrida por su propia entidad. Nadie ha emprendido aún la tarea de analizar la producción periodística de Marx de forma global y sistemática, una labor que demanda tanto la valoración pormenorizada de sus distintos artículos -necesidad del todo urgente por su actualidad y vigor-como un estudio profundo de las relaciones entre su periodismo de investigación y la formación teórica y política de su pensamiento.

Aunque ambas tareas exceden con mucho el contenido de un artículo como éste, cuyo carácter es del todo preliminar respecto a la problemática señalada, en las próximas líneas vamos a tratar de poner de relieve la importancia capital de la producción periodística de Marx en la forja de su "crítica de la economía política". Para ello esbozaremos tres frentes diferenciados de trabajo: 1) para comenzar, realizaremos un breve análisis del olvido de los escritos periodísticos de Marx, tratando de exponer las razones que han propiciado el desplazamiento 
de sus artículos a un lugar secundario dentro de su obra; 2) elaboraremos una propuesta provisional de periodización de la producción periodística del autor, un itinerario de lectura histórico y temáticamente fundado, es decir, atento al pulso de las diversas transformaciones sufridas por el pensamiento de Marx; 3) A partir de lo anterior, y más allá del valor historiográfico de los artículos, mostraremos la relevancia del periodismo de Marx como forma de intervención política en el presente. En este sentido, destacaremos la importancia estratégica de la producción de discursos críticos y coyunturales - cabría decir dialéc$t_{i c o s}{ }^{1}$ - sobre la realidad contradictoria de nuestras sociedades. Una vía de trabajo más que necesaria en pos de participar en un mundo cada vez más complejo y dinámico, un mundo globalizado y en crisis.

Adentrarse en los artículos periodísticos de Marx supone, antes de nada, descifrar las condiciones de su olvido. Como comentábamos más arriba, la tradición marxista ha interpretado las crónicas de Marx de manera unilateral, construyendo una "representación" o "imagen" de las mismas harto esquemática y simplificadora. Una representación que contiene, además, un matiz peyorativo: el menosprecio de cierta cultura filosófica y científica hacia una ocupación intelectual "menor" como el periodismo. Este prejuicio, un prejuicio que ha perdurado a lo largo de diversas lecturas e interpretaciones de su pensamiento, tiene su origen en una interpretación excesivamente literal del testimonio de Marx, cuya relación con el periodismo fue siempre tensa y difícil. Quizá sea pertinente recordar que la mayoría de los periódicos en los que colaboró el filósofo acabaron súbitamente cerrados: asediados por la censura o sin fuentes de financiación. Tales fueron los casos de la Rheinische Zeitung (1842-42), los Deutsche-französische Jahrbucher (1843-44), Vorwärts! (1844), la Neue Rheinische Zeitung (1848-49) o la Neue Rheinische Zeitung. Politische-Öknomische Revue (1850). Cabe también señalar que la relación más duradera e importante que Marx mantuvo con un diario, el Norteamericano New York Tribune (1852-1862), se vio sacudida constantemente por diferencias y conflictos con sus editores.

\footnotetext{
${ }^{1}$ Hablamos aquí de dialéctica en el sentido en que lo hace Manuel Sacristán; es decir: un discurso que no se basa en el método analítico-reductivo de las ciencias empíricas, sino en un trabajo de sintesis que reconstruye -a partir de los datos de las ciencias socio-históricas-totalidades concretas atravesadas por contradicciones. Dialéctica significa aquí el trabajo de "individualización" de una coyuntura social, económica y política realizado para obtener una visión global en un momento específico. Una visión cuyos objetivos son de carácter político y antagonista. Ver: Manuel Sacristán, La tarea de Engels en el Anti-Dühring en Sobre Dialéctica, El Viejo Topo, Barcelona 2009.
} 
La "representación unilateral” de la obra periodística de Marx -aquella que trata sus artículos como algo secundario ${ }^{2}$ - toma como referencia varias cartas y declaraciones del filósofo en las que éste critica duramente el ejercicio del periodismo, ya sea aludiendo a dificultades con la censura o expresándose sobre los pormenores del trabajo de corresponsal (problemas económicos, desacuerdos editoriales, descuido de sus trabajos científicos por atender al periodismo etc.). Muchas son conocidas, y atraviesan varias etapas de su trabajo como corresponsal: las cartas de Marx a Ruge tras la notificación de censura y cierre de la Rheinische Zeitung, el enfado de Marx - acusado de publicar prensa sediciosa — ante la supresión de la Neue Rheinische Zeitung y su posterior expulsión de Colonia, pero también las constantes discusiones epistolares entre Karl Marx y Friedrich Engels sobre la editorial del New York Tribune (Charles Dana y Horace Greely). Es especialmente en este último período, que marca la etapa más importante en la producción periodística del filósofo, cuando las críticas hacia el periodismo como actividad afloran con más violencia en sus cartas. Sin embargo, el Tribune era el periódico con más tirada de la época, y gracias a él Marx comenzó a ser conocido en la nación capitalista que pronto arrebataría la hegemonía mundial a Inglaterra, Estados Unidos. Por tanto, y a la luz del prestigio adquirido en el rotativo, sus críticas al periodismo podrían resultar paradójicas. Pero en absoluto lo son cuando situamos históricamente el trabajo del filósofo: la década de 1850 fue probablemente la más dura para Marx en términos biográficos y vitales, su única fuente de ingresos era el periodismo, al cual debía dedicar la mayor parte de su tiempo para sobrevivir. No obstante, como puede verse a lo largo de su epistolario de este período, el periodismo no era suficiente, y la familia Marx debía pedir regularmente ayuda económica a Engels para no caer en la miseria. Como es lógico, su labor como corresponsal no dejaba de retrasar los "estudios científicos" proyectados por el filósofo, haciéndole posponer continuamente la escritura de una obra que llevaba por título "Economía".

\footnotetext{
${ }^{2}$ Utilizamos el rótulo de "representación unilateral" para englobar-de manera esquemática y general- un grupo de actitudes y valoraciones sobre la obra periodística de Marx que la entienden como algo menor, prescindible a la hora de analizar seriamente su pensamiento. Han sido muchos los discursos que han perpetuado esta consideración, y muchas las estrategias: desde descuidar en términos absolutos su trabajo periodístico o censurar parte de sus textos, como hiciera el marxismo soviético, a considerarlo un género menor o "de juventud", como hiciera Louis Althusser. Galvano Della Volpe, que trabaja en el mismo horizonte histórico y epistemológico que Althusser respecto a Marx (dando especial relevancia a su Einleitung de 1857), tampoco considera con seriedad sus artículos de la década de los 50. Ver: L. Althusser, Pour Marx, La Découverte, París 1996, Lire le Capital, PUF, París 1996; G. Della Volpe, Logica come scienza storica, Editori Riuniti, Roma 1969 y Rousseau e Marx e altri saggi di critica materialistica, Editori Riuniti, Roma 1974.
} 
El epistolario de Marx durante su corresponsalía para el Tribune está lleno de desacuerdos, críticas e incluso arrebatos de desprecio hacia sus editores. Las razones, más allá de las presiones materiales a las que el autor se veía sometido, tenían que ver con la recepción y el uso de sus artículos por parte del diario. Lo más grave para Marx era que el Tribune solía imprimir sus crónicas como editoriales $^{3}$ sin consultarle, ignorando muchos otros textos que jamás aparecían publicados y de los que finalmente no tenía noticia alguna. El filósofo se veía sometido a unos criterios de edición que - a su parecer - rayaban en lo superficial y lo arbitrario. La tensa relación con el diario neoyorquino le haría realizar declaraciones como esta: "El continuo estercolero periodístico me aburre. Me ocupa mucho tiempo, dispersa mis esfuerzos y, finalmente, no es nada. Por independiente que uno quiera ser, todavía depende del periódico y del público, especialmente si, como hago yo, se recibe pago en dinero. Las obras puramente científicas (Rein wissenschaftliche Arbeiten) son algo completamente diferente...". Además, el interés del Tribune por la "alta política" internacional, más digerible por el gran público y menos importante para el corresponsal, contribuía a que su relación con el diario fuese siempre conflictiva ${ }^{5}$. La crisis económica mundial de 1857 —momento en que el filósofo comenzó sus Grundrisseincrementará el malestar entre Marx y la junta editorial, un hecho que unido a las pérdidas del diario terminaría poniendo fin a su carrera cinco años después. Durante el año de la crisis, y ya inmerso en sus esbozos, escribirá así a Lassa1le: "Me he esforzado por trabajar durante el día para ganarme la vida. Sólo me queda la noche para los trabajos auténticos (wirkliche)..." ${ }^{\text {. }}$. Del epistolario de Marx de este período, abordado aquí de un modo esquemático, podría sacarse apresuradamente una conclusión: que para el filósofo el periodismo constituía "solamente" un trabajo para "ganarse la vida", un trabajo subalterno e inferior a su obra teórica. Razonamiento que parece reforzarse debido a la distinción trazada por el autor entre sus "trabajos auténticos" (científicos) y ese "estercolero periodístico" que "no era nada".

Una lectura demasiado inmediata de las cartas de Marx nos condena a reproducir la citada opinión, sobre todo si tendemos a privilegiar la "problemática cien-

\footnotetext{
${ }^{3}$ Publicar un artículo como "editorial” suponía borrar del mismo su autoría, integrándolo en el diario como texto relevante al precio de perder la firma del articulista. Esto enfurecía a Marx, y lo hacía sobre todo porque el diario no le consultaba nunca si deseaba que sus escritos tuviesen ese destino.

${ }^{4}$ Carta de Marx a Adolf Cluss, 15 de Septiembre de 1853. MEW. Bd 28. Pág. 592.

5 "Resulta decepcionante, en efecto, verse condenado a considerar como una suerte que semejante papel te acepte en su barco. Roer los huesos, molerlos y hacer con ellos una sopa como los "paupers" en la "workhouse", he aquí a qué se ve reducido el trabajo político al cual se está condenado en esta empresa". Carta de Marx a Engels, 23 de Enero de 1857. MEW, Bd. 28, Pág. 102.
} 
tífica" de su pensamiento frente a otras facetas de su actividad intelectual. Este ha sido el caso de la recepción de su obra por las corrientes del llamado Marxismo Occidental a lo largo del siglo XX. Louis Althusser, Galvano Della Volpe y Lucio Colletti hicieron cristalizar una lectura académica de Marx que se centró, esencialmente, en una interpretación de los "escritos científicos" y de "madurez" del filósofo desde una óptica epistemológica (Althusser en una línea estructuralista, Della Volpe y Colletti desde los presupuestos de la Ciencia Moderna). Fue el momento de ir en búsqueda de las coordenadas teóricas del pensamiento de Karl Marx, de explicitar los presupuestos científicos de su "ciencia" para combatir las ideologías dominantes en el campo de las ciencias humanas. También fue la ocasión para proponer un programa de investigación social que finalmente quedó reducido a mera hermenéutica. El Marxismo Occidental, tal y como señalara Perry Anderson ${ }^{7}$, compensaba en el ámbito cultural la debilidad política de los intelectuales comunistas occidentales, separados de los órganos de decisión de los partidos casi desde los inicios de la III Internacional. Un hecho que sumado al perfil filosófico y universitario "puro" de estos pensadores, los situaba cada vez más lejos de los movimientos sociales y populares, es decir, de la realidad antagónica de la sociedad. Aunque no es este el espacio para valorar de forma exhaustiva las diferentes apuestas y límites de estas corrientes, debemos señalar uno de los efectos más importantes de su producción filosófica y epistemológica: al instituir una marco de trabajo enfocado hacia los "textos de madurez" de Marx, aquellos en los que podía rastrearse la metodología más desarrollada del marxismo, estas tradiciones dejaron a un lado todos los escritos que no tenían cabida en ese canon. Esto no sólo incluyó los escritos periodísticos de Marx, que fueron menospreciados, sino también, por ejemplo, los Grundrisse, cuyo lenguaje hegeliano no encajaba bien en la imagen del "Marx maduro" ofrecida por Althusser y Della Volpe. De este modo, la tradición del Marxismo Occidental sirvió de "barrera" para una aproximación sistemática a los artículos del filósofo de Tréveris, una barrera o bloqueo que se ha prolongado hasta nuestros días.

Ahora bien, tomando cierta distancia reflexiva y situándonos históricamente dentro de la obra de Marx, el panorama que aparece ante nosotros es muy diferente del dibujado por estas lecturas. Para empezar, el hecho de que Marx criticase su actividad periodística justo en el momento de su mayor producción, llegando a separar incluso su trabajo científico del periodístico, no debe hacernos caer en la trampa de minusvalorar su labor como cronista. Desde una perspectiva biográfica, su epistolario traduce las tensiones materiales de la década de 1850, la precarie-

\footnotetext{
${ }^{7}$ Perry Anderson, Consideraciones sobre el marxismo occidental, Siglo XXI, Madrid 1979.
} 
dad económica y la lucha de la familia de Marx para salir de la miseria. Si estos elementos no son tomados en cuenta, no puede entenderse su aparente "desprecio" por el periodismo. Sucede lo mismo si no se alude a las disensiones con los editores del Tribune o, de un modo más general, a sus conflictos con la censura política en su trayectoria periodística. Pero más allá de esto, hay dos cuestiones que otorgan al periodismo un papel de primera importancia en la formación del pensamiento de Marx. A pesar de que en la década de los 50 hablase del periodismo como una ocupación puramente "laboral", si ponemos en perspectiva su trayectoria intelectual la realidad es otra: su interés periodístico data de 1842, y su trabajo como redactor le acompañaría de forma casi ininterrumpida hasta 1862 , época en la que ya había esbozado las líneas generales de su crítica de la economía política $^{8}$. La actividad periodística es, por tanto, una dinámica fuertemente enraizada en la matriz de su pensamiento teórico-político. De hecho, su participación en la fundación de diversas revistas en la década de los 40 es muy significativa (desde los Deutsche-französische Jahrbucher hasta la Neue Rheinische Zeitung. Politische-Ökonomische Revue). Y es que Marx pensaba que el periodismo era una herramienta esencial de análisis y difusión para su tarea crítica y política. Yendo algo más lejos, y relacionando ahora la producción teórica y periodística del pensador, podemos afirmar que difícilmente puede comprenderse el alcance de la crítica de la economía política madura del filósofo sin los artículos del Tribune, ya que fue gracias a ellos, gracias a sus análisis y a las investigaciones acometidas para escribirlos, que Marx pudo desarrollar una comprensión madura del mercado mundial, la clase obrera, las crisis, la ciencia económica, la historia y la tecnología. Una serie de conocimientos sin los que no habría podido escribir un texto como los Grundrisse entre 1857 y 1858 . Frente a las lecturas demasiado inmediatas o esencialmente epistémicas de Marx, ha de señalarse que el periodismo es un aspecto central del pensamiento del filósofo, una actividad regular que le acompaña desde los inicios de su aventura intelectual. Una práctica que no sólo le permitía intervenir políticamente, sino que - como no podía ser de otro modo - tendría efectos y resonancias teóricas fundamentales en la forja de su pensamiento maduro.

\section{Periodización: etapas y transiciones.}

Siguiendo criterios históricos, teóricos y políticos podemos construir una periodización cronológica y temática de la actividad periodística de Marx. Se trata de poner de relieve las coordenadas teóricas y la ideología política que rigen en cada

\footnotetext{
${ }^{8}$ Materializadas en los Grundrisse (escritos entre 1857-58) y la Contribución a la crítica de la economía política (escrita entre 1858 y comienzos de 1859).
} 
fase de su producción periodística, señalando, al mismo tiempo, el papel de dicha etapa en la formación de su pensamiento como un todo. En un texto como este, del todo introductorio, no podremos ser exhaustivos, de modo que procuraremos ofrecer una periodización esquemática pero bien fundada, una presentación útil para adentrarse en el periodismo del filósofo de Tréveris. Será esencial marcar en cada fase las diferentes transiciones evolutivas del pensamiento de Marx, de modo que puede verse la relación dialéctica existente entre periodismo, teoría y política:

- Primera etapa (1842-43): Marx comienza en 1842 su trabajo como corresponsal en la Rheinische Zeitung, escribiendo desde un marco ideológico liberal, ilustrado y progresista. La gaceta estaba fundada con el capital de varios industriales de Renania, y entre sus objetivos figuraban la lucha por el libre comercio, la ampliación de los derechos civiles y la reforma de las estructuras feudales del Estado Prusiano (especialmente en lo que éstas afectaban a Renania, que durante la ocupación francesa había gozado de un código civil liberal). Los temas fundamentales de este período son la lucha contra la censura, la desigualdad social y un acercamiento a posiciones socialistas gracias al análisis de diversos problemas socio-políticos (la miseria campesina, la ley del divorcio, la feudalización de Renania por parte del gobierno de Prusia). Estos escritos de Marx traducen, sobre todo, la evolución de una Alemania predominantemente rural hacia una economía capitalista e industrial, cuyo precio comenzaban a pagar las clases trabajadoras y campesinas. Estas clases se vieron desposeídas de su acceso a bienes tradicionalmente comunes (como, por ejemplo, la madera), condenadas a una miseria artificial provocada por la incipiente economía de mercado. La serie de artículos contra la censura, el robo de leña y aquellos que criticaban la situación de los campesinos viticultores del Mosela ${ }^{9}$, hicieron enfurecer al gobierno de Prusia, que "suprimiría" el periódico con tan sólo un año de vida. El joven filósofo pensaba que la crítica libre y abierta podía servir para cambiar las estructuras del Estado prusiano, unas estructuras que consideraba - como buen ilustrado- racionales y capaces de dotar de igualdad y libertad al pueblo soberano. Pero la respuesta del Estado sería bien distinta: represión, censura, supresión de publicaciones críticas y un conservadurismo temeroso de cualquier reforma democrática. El Estado, lejos de responder a la soberanía popular, parecía estar al servicio de los intereses de ciertos sectores dominantes, revelándose irracional y contrario a su función ilustrada. El liberalismo progresista de Marx entraba así en crisis, abriendo las puertas al socialismo.

${ }^{9}$ Existe una buena edición y traducción de estos escritos en castellano: En defensa de la libertad: los artículos de la Gaceta Renana 1842-1843, edición a cargo de Juan Luis Vermal, Fernando Torres D.L., Valencia 1983. 
- Segunda etapa (1843-1844): tras el cierre de la Rheinische Zeitung Marx se embarcará en otro proyecto periodístico junto a Arnold Ruge, antiguo colaborador del diario renano: los Deutsche-französische Jahrbücher. La línea ideológica de la revista estuvo influenciada tanto por la realidad del proletariado francés realidad que Marx conocería al emigrar a París - como por el pensamiento de Ludwig Feuerbach. Este nuevo horizonte político-intelectual lo alejará del liberalismo y de la cultura intelectual dominante en Alemania, que seguía planteándose los problemas sociales en los términos metafísicos de G.W. F. Hegel. En los Jahrbücher el pensador cambiará el estilo periodístico de su anterior rotativo, enfocado hacia la la noticia de actualidad, para adentrarse en el terreno del ensayo filosófico-político. Como señalábamos, la evolución teórica de Marx hacia el socialismo debe mucho a la antropología filosófica y humanista de Feuerbach, de la que hereda sus conceptos fundamentales. No obstante, el joven pensador no se limitará a asumir pasivamente la teoría feuerbachiana de la alienación, sino que se apropiará de ella de manera original, imprimiéndole un filo político que ésta no poseía. El Estado prusiano aparecerá ahora ante el filósofo como una estructura política que impedía que la esencia humana -universal, colectiva y comunitaria- pudiera expresarse en libertad. La esencia del hombre se encontraba enajenada en la sociedad prusiana, pues las relaciones existentes entre el Estado y la sociedad civil provocaban la escisión de cada individuo en dos facetas irreconciliables: el individuo como trabajador y el individuo como ciudadano. Lo que latía en el fondo de los análisis de Marx en escritos como La cuestión judía o la Introducción a la Crítica de la filosofía del derecho de Hegel — ambos publicados en los Jahrbücher — era el conflicto cada vez más agudo entre el mundo del trabajo, el mercado y un poder estatal anti-democrático. Pero resolver la contradicción entre la sociedad civil y el Estado pasaba por que la esencia del hombre se expresase sin trabas; los hombres necesitaban unas instituciones políticas a la altura de su "ser comunitario", capaces de poner fin a la enajenación colectiva a la que se veían sometidos.

Marx descubrirá que la "esencia de la humanidad" se hallaba en la clase que soportaba el peso del mundo moderno, su miseria y violencia: la clase trabajadora. Era ella, como sujeto de la desigualdad universal, la que debía destruir sus cadenas para liberar, al mismo tiempo, a toda la humanidad de las contradicciones del capitalismo. Marx asume así una mirada socialista — casi comunista — de la realidad política y económica, aunque ésta se encuentre todavía expresada en términos filosóficos. Su salto definitivo hacia el comunismo lo dará en 1844, cuando escriba para Vorwärts! y esboce sus conocidos Manuscritos de París, dando forma a su primer y juvenil "crítica de la economía política". El cierre de los Deutsche-französische Jahrbücher y la supresión de Vörwarts! en 1844 —ambos clau- 
surados por la presión de Prusia_ - llevaría a Marx a un silencio periodístico de 4 años, un tiempo que dedicará al estudio y al activismo político.

- Tercera etapa (1848-1850): Karl Marx volverá al periodismo a raíz de las revoluciones europeas de 1848, y lo hará desde posiciones netamente comunistas. En aquellas fechas el filósofo había elaborado ya las hipótesis y conceptos fundamentales del materialismo histórico. Escritos como La Ideología Alemana (co-escrito con F. Engels entre 1845-46), la Miseria de la Filosofia (1847) y El Manifiesto del Partido Comunista (1848) forman parte de una transición teórica que llevará a Marx a un terreno que sólo había comenzado a explorar en el 44: la investigación histórica y económica. El contenido de dichos escritos influirá decisivamente en su nuevo periodismo, que abandonará el terreno conceptual y la forma del ensayo para adentrarse en el ámbito de lo concreto a través de la noticia. Este movimiento hacia lo empírico permitirá al filósofo desarrollar una crítica materialista renovada, de vocación totalizadora, cuya potencia se revelará a lo largo de sus análisis sobre el 48. Retomando el hilo de la teoría, ha de señalarse que La Ideología Alemana y El Manifiesto del Partido Comunista dibujan una trama conceptual novedosa, alejada del lenguaje feuerbachiano de los escritos anteriores del filósofo: fuerzas productivas, división social del trabajo, modo de producción, relaciones de producción e intercambio, clases sociales, lucha de clases, etc. Pero además, ambos escritos construyen una narrativa histórica que permite cifrar la génesis de las desigualdades y los conflictos de la sociedad moderna, proponiendo diversas hipótesis de investigación (centralidad de la producción material, lucha de clases, dinámicas de acumulación, etc.) capaces de totalizar varios procesos socio-históricos en un mismo marco analítico. Por otra parte, la Miseria de la Filosofía mostraba ya una comprensión crítica y general de la economía política y sus teóricos principales, avanzando algunos de los argumentos que más adelante darán forma a la teoría marxiana del valor-trabajo.

Entre Junio de 1848 y Noviembre de 1850, Karl Marx daría vida a dos proyectos editoriales consecutivos en términos temáticos y políticos: la Neue Rheinische Zeitung (1848-1849) y la Neue Rheinische Zeitung. Politisch-ökonomische Revue (1850), la primera revista sería editada en Colonia y la segunda -continuación de la primera- en Hamburgo. A través de la Neue Rheinische Zeitung Marx ofrecerá un vivo retrato de las revoluciones del 48 en Europa, de su rápida expansión y estrepitosa caída, analizando a lo largo de más de 80 columnas sus acontecimientos más relevantes. Como ya sucediera en otras ocasiones, el periódico sería censurado y finalmente suprimido. Su revista posterior continuará la labor crítica de la primera, pero partirá de un escenario político muy diferente: el del régimen reacciona- 
rio europeo surgido de la derrota popular del 48. El aprendizaje periodístico de esta época, sumado a sus avances en materia de teórica e investigación histórico-económica, permitirán a Marx escribir una pieza histórica de gran calado, La lucha de clases en Francia (1848-1849), así como formular una de las hipótesis centrales de su investigación para la década de los 50: basándose en la crisis del 47 y el estallido del 48, Marx arribará a la conclusión de que el renacer de un movimiento revolucionario sólo podría articularse en torno a una nueva crisis económica ${ }^{10}$.

- Cuarta etapa (1851-1862): la década de los 50 es, sin duda, la más importante en la producción periodística de Marx. Exiliado en Londres, el filósofo comenzará este período retomando sus investigaciones histórico-económicas de manera intensa, continuando su formación y ampliando el espectro de sus análisis más allá de los límites de sus trabajos anteriores. Una de sus primeras y más brillantes contribuciones periodísticas del período será El 18 de Brumario de Luis Bonaparte, texto publicado en varios números del diario norteamericano Die Revolution (1851-52). En él se abordaba de manera satírica la transformación de la República francesa en el Imperio de Napoleón III, analizando los intereses de todas las clases y grupos sociales que -gracias a sus alianzas o enfrentamientos- hicieron posible el advenimiento del nuevo Imperio. Más allá de esta publicación, todo este período viene marcado por su trabajo como corresponsal europeo para el $\mathrm{New}$ York Tribune (1852-62), la asociación periodística más duradera del autor y la más prolífica con diferencia: Marx escribiría unas 350 crónicas periodísticas para el diario de su puño y letra. A este impresionante número de artículos hay que sumar unas 150 columnas más escritas por F. Engels, las cuales aparecieron en el Tribune bajo la firma del filósofo de Tréveris. Fue uno de los modos que encontró Engels para ayudar a Marx en un momento difícil, ya que éste cobraba del diario por artículo entregado. La lista de temas abordados por el autor en este período es casi interminable: análisis sobre las principales economías nacionales de mediados del siglo XIX, sobre el estado del mercado mundial y las crisis comerciales, trabajos sociológicos acerca de la situación de las clases trabajadoras, agudas columnas sobre los principales conflictos políticos europeos, la dominación colonial o las luchas por la emancipación de los esclavos negros en EEUU. Por no hablar de sus lúcidas observaciones sobre la cultura capitalista, fenómenos como el comercio del opio o sus minuciosos informes sobre diplomacia internacional. Esta multitud de líneas temáticas, sólo aparentemente dispersa, tendrá un hilo rojo común: el es-

${ }^{10}$ En castellano existe una edición muy completa de los artículos publicados en la Neue Rheinische Zeitung: K. Marx/F. Engels, Las revoluciones de 1848, FCE, México DF 2006. También puede encontrarse una selección de los artículos publicados en la Neue Rheinische Zeitung. Ökonomkische Politische Revue en K. Marx, Escritos económicos menores, FCE, México DF 1987. 
fuerzo de Marx por construir una crítica de la economía política de carácter verdaderamente global.

En medio de su trabajo para el Tribune, y tras haber escrito varios artículos anunciando una posible crisis general ${ }^{11}$, estallará el pánico de 1857 , dando inicio a la primera gran crisis económica de carácter mundial. Desde el comienzo de la crisis hasta abril de 1858, Marx escribirá los Grundrisse, alternando el trabajo periodístico con la escritura de su obra económica. La conjunción de su madurez periodística con el desarrollo de su bosquejos — boceto inicial de lo que más adelante sería $E l$ Capital - ponen de manifiesto algo que casi siempre pasa desapercibido: que sin la ampliación temática de sus estudios, sin la enorme acumulación de material empírico realizada durante este período gracias a su corresponsalía en el Tribune, Marx no hubiese podido llevar su teoría a la dimensión global que ésta posee en los Grundrisse. Y es que fue la adquisición de esa perspectiva global, debida al profundo examen del funcionamiento de las economías del siglo XIX, lo que le permitió formular un concepto como el de plusvalor y romper con una concepción de la historia lineal y eurocéntrica. De hecho, si hubiese que caracterizar las líneas de "ruptura" del periodismo del Tribune con sus períodos anteriores, habría que señalar al menos cinco características: 1) Una ampliación del marco de análisis del filósofo, que ya no estará enfocado única y exclusivamente a Europa, sino que abordará acontecimientos políticos y económicos a escala global. 2) Una profundización en la comprensión de las relaciones entre trabajo asalariado y capital, que irá de la mano de un análisis histórico de los procesos de acumulación ${ }^{12} \mathrm{y}$ de un estudio del capital industrial y financiero ${ }^{13}$. 3) El acercamiento a culturas no-occidentales (fundamentalmente China y la India), que progresivamente liberará a Marx de muchos prejuicios eurocéntricos y le hará comprender los vínculos del colonialismo con el capitalismo occidental. 4) Una comprensión empíricamente fundada y realista de la lucha de clases, que pa-

\footnotetext{
${ }^{11}$ Por ejemplo, Pauperism and Free Trade. The Approaching Commercial Crisis (1 de Noviembre de 1852) publicado en el New York Tribune. Existe una nueva edición de los escritos periodísticos de madurez de Marx en castellano en la que se encuentran los textos citados: K. Marx, Artículos Periodísticos, Alba Editorial, Barcelona 2013.

${ }^{12}$ En este sentido es esencial el artículo Elections. Financial Cloud. The Duchess of Sutherland and Slavery, publicado en el New York Tribune (9 de Febrero de 1853). Este texto inaugura los análisis históricos sobre los procesos de acumulación de capital, señalando la violencia y la desposesión como herramientas esenciales para acumular capital en forma de tierras, mano de obra o recursos. En el citado texto, Marx aborda la expropiación de los terrenos comunales en Escocia por parte de la aristocracia local.

${ }^{13}$ Por ejemplo, Die Industrie und Handlskrise en la Neue Oder Zeitung (11, 12, 20 y 25 de Enero de 1855) o la increíble serie sobre el Crédit Mobilier francés (The French Crédit Mobilier, 21 y 24 de Junio y 11 de Julio de 1856), uno de los primeros análisis de Marx sobre el capitalismo financiero.
} 
sará tanto por el análisis pormenorizado de la clase obrera industrial inglesa y sus antagonismos como por las diferentes clases subalternas que se rebelaban en las guerras de emancipación de la época: los Cipayos, los movimientos de resistencia chinos y la lucha contra la esclavitud negra. 5) Como consecuencia de todo lo anterior, una comprensión de la historia policrónica ${ }^{14} \mathrm{o}$ multilineal ${ }^{15}$, en ruptura con los esquemas lineales y eurocéntricos asentados en textos como La Ideología Alemana o El Manifiesto del Partido Comunista. Los estudios realizados en la época permiten entender a Marx la existencia de diversas temporalidades, ritmos y cadencias dentro de un mismo período, algo alejado de la dinámica del "progreso" y la "necesidad histórica” tantas veces atribuidas a su pensamiento.

Todos estos cambios pueden seguirse a través de la intersección de los Grundrisse con el periodismo realizado por Marx para el Tribune, concretándose teóricamente en los los análisis de los bosquejos sobre la circulación global, la acumulación y, de un modo central, en el escrito Formas que preceden a la producción capitalista $^{16}$. Gracias a estos escritos podemos entender la dialéctica existente entre el periodismo y la formación teórica del autor.

\section{Una reivindicación del periodismo: mapas antagónicos, imaginarios colectivos}

Lo expuesto hasta aquí pretende mostrar, sobre todo, dos cosas: que el valor historiográfico de los escritos periodísticos de Marx es enorme - sigue siendo una veta inexplorada de su obra- y que sin él resulta imposible entender la evolución de su pensamiento, sobre todo en el momento crítico de la formulación de su teoría madura (1857-58). Pero además, si trazamos un paralelismo entre nuestra época y la de Marx, nos percatamos de la necesidad de seguir insistiendo en aquello en lo

\footnotetext{
${ }^{14}$ En el sentido en que viene usando esta noción Vittorio Morfino en Il Tempo della moltitudine: materialismo prima e dopo Spinoza, Manifestolibri, Roma 2005 y Spinoza e il non contemporaneo, Ombre Corte, Verona 2009. Lo policrónico querría remitir a una pluralidad de ritmos históricos que nunca son contemporáneos u homogéneos, pues no poseen un orden esencial interno que sirva de metron para los mismos (una jerarquía histórica, moral u ontológica) y, por tanto, no pueden ser reducidos a la lógica de una lectura lineal y niveladora (como la ilustrada y occidental del "progreso").

${ }^{15}$ Sobre la "multilinealidad" del enfoque histórico de Marx, el artículo de Kevin B. Anderson publicado en US Marxist Humanists (Diciembre 9, 2009): From the 'Grundrisse'to 'Capital': Multilinear Themes. Disponible en su página personal: http://www.kevin-anderson.com/wpcontent/uploads/docs/anderson-article-from-grundriss-to-capital.pdf

${ }^{16} \mathrm{~K}$. Marx, Elementos Fundamentales para la Crítica de la Economía Política (Grundrisse), Vol. I, Siglo XXI, México DF 2007. Págs. 433-479.
} 
que el periodismo del filósofo ponía el acento: analizar, vincular e intervenir en coyunturas político-económicas que van más allá de lo local o nacional, poniendo en relación antagonismos en un nivel cada vez más amplio. Marx consideró que el periodismo era un arma para poner a trabajar su teoría y llevar a la práctica los objetivos políticos de la clase trabajadora, dando a sus artículos una perspectiva más $p e-$ dagógica y asequible que la que poseen sus obras "científicas". Ello era más que necesario para poder formar una conciencia crítica en el proletariado y en las fracciones de clase dispuestas a escuchar (pequeña burguesía, campesinado, artesanos, etc.); clases que, gracias a estas crónicas, podían disponer de un mapa que reflejaba los conflictos más actuales. Además Marx nunca se limitaba a "dar la noticia", sino que exploraba las causas de los antagonismos en las regiones con mayor actividad económica del mundo, uniendo en una misma trayectoria Estados Unidos, Inglaterra y Francia con algunos de los espacios coloniales más importantes del XIX, como China y la India. Todo ello le permitió, en términos teóricos, entender los ciclos del capital y la mundialización del mercado, pero también le hizo comprender la interrelación económico-politica de la lucha de clases a nivel planetario. Un hecho que se manifestaría en sus análisis políticos (en Europa, Asia y América) y en el modo de abordar la crisis de 1857, en la que quiso ver el indicio de una revolución global que jamás aconteció. No obstante, y a pesar de errar en el 57 con su hipótesis revolucionaria, lo que Marx creaba en sus artículos era información para intervenir y comprender la coyuntura, una cartografía que permitía tejer al lector o lectora de sus crónicas una imagen del mundo moderno con todas sus desigualdad y violencia. De este modo, Marx daba forma a un imaginario colectivo y antagonista que, si bien participaba del exotismo orientalista del XIX y de una mirada deudora del capitalismo como "factor de desarrollo", era capaz de representar algunos de los conflictos más centrales del capitalismo mundial de su siglo. Lo cierto es que su trabajo en el Tribune le haría romper con los prejuicios eurocéntricos heredados de Hege ${ }^{17}$ y de una tradición histórico-filosófica de carácter colonial, dotándole de

\footnotetext{
${ }^{17}$ Para valorar esta ruptura es necesario recorrer los artículos de Karl Marx sobre la India, que comienzan siendo deudores de Hegel para, poco a poco, llevar a Marx a un doble desengaño: 1) desengaño con la historia trazada bajo la égida del progreso, en la que hay culturas "superiores" a otras según un patrón occidental de desarrollo histórico (patrón cultural apuntalado por Hegel en sus Lecciones sobre Filosofia de la Historia). 2) desengaño con el capitalismo como "fuerza de progreso y emancipación" en las sociedades no-occidentales. Marx comprobaría como el capital constituía sobre todo, y por encima de otras determinaciones, un eje de explotación y acumulación de recursos para las potencias económicas en los territorios coloniales. El capital sólo "modernizaba" al precio de destruir y hacer miserable a la población de la periferia capitalista, destruyendo su cultura y acrecentando sus contradicciones comunitarias con nuevas relaciones de poder. En este sentido: Kevin Anderson, Marx at the margins:On Nationalism, Ethnicity, and Non-Western Societies, The University of Chicago Press, USA 2010.
} 
una visión más profunda de los problemas que definían el sistema-mundo moderno. Una visión que sólo pudo ganar - insistimos — gracias a su labor como cronista.

Asumir hoy el legado periodístico de Marx debería pasar, antes de nada, por una tarea: integrar el periodismo en la obra de Marx como una producción literaria de primer orden, favoreciendo su análisis y comprensión histórica. Y ello no sólo dentro de la trayectoria intelectual del autor, sino con relación a los fenómenos políticos, sociales e históricos que examina en sus columnas. El estado actual del marxismo, cada vez más alejado del "teoricismo", debería favorecer un estudio que además de legítimo es necesario si se desea profundizar en el pensamiento de Marx, en el siglo XIX y en ese tipo de análisis coyunturales que realizaba el filósofo; análisis que sintetizaban en su fondo el sub-texto de la época: el formado por las dinámicas materiales de la misma, los ciclos de acumulación del capital y la lucha de clases. Pero asumir la singularidad de estos escritos debería obligarnos también a "repetir" su esfuerzo, y de forma apremiante: es necesario llevar a cabo lo que el filósofo hizo en su época en un momento —el presente - en que las relaciones de producción y el desarrollo de las fuerzas productivas han mutado considerablemente. Hoy día los antagonismos y sus identidades se han expandido, y las formas dominantes de la relación capital han virado hacia la financiarización en un sentido global. La composición de la fuerza de trabajo a escala mundial es increíblemente compleja: trabajadoras y trabajadores de cuello rosa en occidente, proletariado industrial en países económicamente pujantes como China o primacía de la agricultura y la industria extractiva en diversas naciones del continente africano, etc. Sin embargo, y pese a estas transformaciones, la perspectiva alcanzada por Marx en sus escritos del Tribune era la adecuada: una perspectiva sintética de los múltiples conflictos que se presentaban en el escenario mundial. Conflictos acompañados de un imaginario colectivo compartido, una serie de valores y prácticas en las que el proletariado podía reconocerse, tomar consciencia y situarse. Si hoy día queremos responder a la ofensiva neoliberal que está destruyendo la sociedad, aumentando la explotación y precarizando la vida de las clases trabajadoras, hemos de realizar análisis y diagnósticos que sirvan de mapa social para poder actuar. Cartografías capaces de reunir lo dispar en un relato común que nos permita cuestionar los consensos políticos neoliberales y la pasividad adquirida a lo largo de décadas. Sólo a partir de este tipo de trabajos un proletariado multi-étnico, precario y con género tendrá la posibilidad de convertirse en agente socio-político de su vida; sólo así - generando conciencia — podremos construir una alternativa a este capitalismo depredador, un sistema al que no le importa sacrificar millones de personas si con ello mantiene alta su tasa de beneficio. En este sentido, el periodismo realizado por Marx tiene mucho que enseñarnos, y nosotros mucho que aprender de él desde nuestro horizonte en crisis. 


\section{BIBLIOGRAFÍA}

Althusser, Louis, Pour Marx, La Découverte, París 1996

Althusser, Louis, Lire le Capital, PUF, París 1996

Anderson, Kevin, From the "Grundrisse" to "Capital”: Multilinear Themes 12/09/2009 http://www.kevin-anderson.com/wp-content/uploads/docs/anderson-article-from-grundriss-to-capital.pdf

Anderson, Kevin, Marx at the margins:On Nationalism, Ethnicity, and Non-Western Societies, The University of Chicago Press, USA 2010.

Anderson, Perry, Consideraciones sobre el marxismo occidental, Siglo XXI, Madrid 1979.

Della Volpe, G.., Logica come scienza storica, Editori Riuniti, Roma 1969

Della Volpe, G.., Rousseau e Marx e altri saggi di critica materialistica, Editori Riuniti, Roma 1974.

Hobsbawm, Eric, La Era del Capital 1848-1875, Crítica, Barcelona 1988

Marx, Karl, Marx Engels Werke, Diet Verlag, Berlín 1963, Band 28

Marx, Karl, Marx Engels Werke, Diet Verlag, Berlín 1978, Band 29

Marx, Karl, En defensa de la libertad: los artículos de la Gaceta Renana 1842-1843, Fernando Torres D.L., Valencia 1983.

Marx, Karl, Las revoluciones de 1848, FCE, México DF 2006

Marx, Karl, Escritos económicos menores, FCE, México DF 1987.

Marx, Karl, Artículos Periodísticos, Alba Editorial, Barcelona 2013

Marx, Karl, Elementos Fundamentales para la Crítica de la Economía Política (Grundrisse), Siglo XXI, México DF 2007, Vol. I-III

Meiksins-Wood, E., The Origin of Capitalism: a Longer View, Verso Books, New York 2002

Morfino, Vittorio, Il Tempo della moltitudine: materialismo prima e dopo Spinoza, Manifestolibri, Roma 2005

Morfino, Vittorio, Spinoza e il non contemporaneo, Ombre Corte, Verona 2009

Musto, Marcelo, Karl Marx's Grundrisse. Foundations of the critique of political economy 150 years later, Routledge, New York 2008

Sacristán, Manuel, Sobre Dialéctica, El Viejo Topo, Barcelona 2009

Sacristán, Manuel, Sobre Marx y marxismo. Panfletos y materiales I, Icaria, Barcelona 1983 